\author{
NATHÁLIA DE MOURA MENDES \\ FERNANDA VASCONCELOS DE OLIVEIRA
}

Os desafios enfrentados por alunos deficientes visuais em curso superior de Ciências Biológicas 


\section{$-8$ \\ virctur \\ Centro Unıversıtárıo de Brasílıa}

NOME DOS ALUNOS

NATHÁLIA DE MOURA MENDES

FERNANDA VASCONCELOS DE OLIVEIRA

Os desafios enfrentados por alunos deficientes visuais em curso superior de Ciências Biológicas

Relatório final de pesquisa de Iniciação Científica apresentado à Assessoria de Pós-Graduação e Pesquisa pela Faculdade de Ciências da Educação e da Saúde - FACES.

Orientação: Bianca Carrijo Cordova

\section{BRASÍLIA-DF \\ 2016}




\title{
Os desafios enfrentados por alunos deficientes visuais em curso superior de Ciências Biológicas
}

\author{
Nathália de Moura Mendes - UniCEUB, PIC voluntário \\ mendesnmbio@gmail.com
}

\begin{abstract}
Fernanda Vasconcelos de Oliveira - UniCEUB, PIC voluntário fernandavso@gmail.com
\end{abstract}

\section{Bianca Carrijo Cordova - UniCEUB, professora orientadora bianca.cordova@uniceub.br}

O curso superior de Ciências Biológicas possui uma alta demanda de atividade visual em suas disciplinas, seja para a visualização de estruturas básicas, entendimento de mecanismos ou também para a utilização de microscópios. Seguindo este contexto, esse estudo consistiu em uma busca para entender e avaliar técnicas e mecanismos utilizados em salas de aula que possuem alunos com deficiência visual (baixa visão ou cegueira) e identificar por parte dos professores e dos próprios alunos, as demandas e necessidades que ainda eram apresentadas apesar do uso de outros recursos. O estudo buscou reunir informações bibliográficas de trabalhos já publicados para criar 3 (três) materiais didáticos de diferentes áreas das Ciências Biológicas com a finalidade de auxiliar os professores de diferentes IES (Instituições de Ensino Superior) que atuam com este tipo de público dentro deste curso durante o ensino de suas disciplinas e também facilitar o aprendizado dos alunos por meio do uso de materiais que os ajudariam a entender melhor conceitos que geralmente são abstratos para aqueles que possuem deficiência visual. As áreas identificadas com a maior demanda de matérias didáticos devido a grande quantidade de material visual foram os campos da genética, botânica e microbiologia. A partir deste levantamento, foram criados materiais táteis e texturizados sendo também auxiliados pelo uso do braille. Para a genética, foi criado um painel exemplificando o processo de formação do cromossomo, utilizando uma imagem didática que é apresentada em sala de aula para a modelagem em alto relevo. Na área da botânica, o painel continha as informações sobre as partes internas de uma flor em alto relevo, este também foi criado a partir de uma imagem didática. Para a área da microbiologia, foi montado um vírus bacteriófago em modelagem 3D auxiliado pelas texturas e alto-relevo. Os materiais propostos e criados neste estudo poderão ser validados em estudos posteriores e recriados por grupos interessados no assunto dentro das IES, possibilitando assim uma expansão do aprendizado desta área para qualquer aluno, incluindo os sujeitos com alguma deficiência visual.

Palavras-chave: Inclusão. Materiais didáticos. Cegueira. Baixa visão. Ensino Superior. 


\section{INTRODUÇÃO}

Existem dois tipos de pessoas cegas: aquelas que nunca enxergaram, e os que em algum dia de suas vidas enxergaram e por algum motivo foram privados desse sentido. O primeiro grupo é os dos cegos congênitos e o segundo grupo, o de pessoas com cegueira adquirida (CAROLL, 1961).

A deficiência visual engloba dois grupos diferentes: os cegos e as pessoas com baixa visão. O Ministério da Educação (MEC) define cegueira como "acuidade visual igual ou menor que 0,05 no menor olho, com a melhor correção óptica ou a ausência total de visão até a perda da percepção luminosa" e baixa visão como "acuidade visual entre 0,3 e 0,05 no melhor olho, com a melhor correção óptica" (BRASIL, 2015, pg. 46).

Mas, como é a educação oferecida a alunos com essas condições? De acordo com Castro et al (2015), a educação inclusiva é baseada na Declaração Universal dos Direitos Humanos, e defende a igualdade de ensino para todas as pessoas em suas diferentes necessidades, dando a elas o direito de participar e aprender em conjunto independente de suas limitações.

Vargas (2006) destaca a importância de saber as diferenças entre inclusão e integração. Visto que a primeira é a adaptação da Instituição de Ensino (IE) às necessidades de seus alunos, e a segunda, é a adaptação do aluno às normas da IE para que o mesmo seja aceito no ambiente educacional. Essa inclusão da qual fala Vargas deve estar presente em todos os níveis de ensino, incluindo o ensino superior.

Quanto a esta modalidade de ensino, Holanda (2011) diz que para o ingresso no ensino superior, não poderá haver discriminações, sejam elas sociais, religiosas, culturais ou físicas. Todos os grupos devem possuir a mesma facilidade de acesso às universidades e ao ensino. $O$ autor também reforça a importância de se realizar uma inclusão completa, que vai além do ato político, reforçando sempre que a pessoa a ser incluída deve ser aceita com suas limitações e dificuldades.

De acordo com Faria (2012) desde a implantação de novas políticas públicas para alunos com Necessidade Educacionais Especiais (NEE), as universidades tem 
se preparado cada vez mais para receber esse tipo de aluno e abrir novas portas para o acesso e a inclusão dos mesmos no ensino superior.

Vale ressaltar que inclusão da pessoa com deficiência dentro do ambiente das Instituições de Ensino Superior é uma discussão ainda muito recente e carece de estudos e pesquisas mais a fundo. Essa discussão abre também para a observação da preparação dos professores universitários na recepção desses alunos e deixa espaço para a discussão e formulação de novas metodologias de trabalho (VARGAS, 2006).

Tendo em vista que o curso superior de Ciências Biológicas possui altas demandas de atividade visual e de capacidade de abstração, o presente trabalho objetivou realizar uma revisão teórica, propor e criar três materiais didáticos que poderão ser utilizados por alunos deficientes visuais ou com baixa visão para o propósito da aprendizagem das matérias do curso.

\section{FUNDAMENTAÇÃO TEÓRICA}

Segundo Schüetzer (2015), a educação inclusiva no Brasil começou a receber demanda para alunos com deficiência visual no século XIX. Porém, apenas a partir do século $\mathrm{XX}$, a pedagogia começou a procurar meios diferentes para trabalhar com alunos com Necessidades Educacionais Especiais (NEE).

Schüetzer (2015, pág. 49) conceitua inclusão como "o esforço para que as pessoas com deficiência convivam plenamente em todos os ambientes sociais" e que esse esforço implica diretamente em acessibilidade. Sassaki (2005) diz que a IE inclusiva (não a integrada), deve ser completa em seis dimensões de acessibilidade:

- Arquitetônica: ambientes externos e internos sem barreiras físicas;

- Comunicacional: o ambiente educacional deve possuir todas as formas de comunicação com seu aluno (LIBRAS, gestual, braile, ledores, textos ampliados, entre outros);

- Metodológica: as técnicas e metodologias de estudo devem ser adaptadas para todas as inteligências.

- Instrumental: todos os materiais e instrumentos de estudo e educação devem e podem ser utilizados por qualquer tipo de aluno;

- Programática: não devem haver barreiras em politicas públicas ou regulamentos que limitem o acesso a educação; 
- Atitudinal: sensibilização das pessoas no convívio social para a quebra de preconceitos e estereótipos.

De acordo com Santos e Mendonça (2015), desde o ano de 2003 o número de alunos com algum tipo de deficiência em IES aumentou consideravelmente. Esse fato começou a levantar nas áreas de pesquisa em educação o seguinte questionamento: os professores universitários estão preparados para receber alunos com NEE em suas salas de aula? As universidades possuem estrutura física e educacional para atender essas demandas?

No processo de aprendizagem, o papel do professor é fundamental. Por meio deste é que se dá não só o desenvolvimento de conteúdos, mas suas interpretações e definições. A partir disto, objetiva-se uma mudança na pedagogia tradicional visando o ensino e aprendizagem de alunos com deficiência, de forma que o formato das aulas possibilite a inclusão real desses alunos, permitindo que eles tenham o mesmo acesso aos conteúdos que alunos sem deficiência (SANTOS E MENDONÇA, 2015).

Segundo Costa e Barros (2014, pág. 82) "a imaginação e a curiosidade também constituem um diferencial no momento da aprendizagem científica", porém para alunos videntes - aqueles que possuem visão normal -, a imaginação e curiosidade científica são em boa parte, sanados com imagens ou práticas para as representações biológicas dos conceitos que Ihes são ensinados.

Nepomuceno et al (2015), diz que alunos com deficiência visual geralmente são desencorajados a participar de atividades envolvidas com as ciências, uma vez que precisariam sempre de suporte, supervisão ou não conseguiriam executar as atividades comumente como os alunos videntes (aqueles que enchergam normalmente).

As diversas representações de conceitos no Ensino da Biologia por meio de imagens e práticas experimentais acabam por afastar o aluno deficiente visual da exploração mais aprofundada dos mesmos. Sabendo da forma e do porque se dá esse distanciamento, podemos justificar o uso de recursos didáticos como uma aproximação da realidade científica e dos conceitos abstratos apresentados a esses alunos (ARAGÃO, 2012).

Vaz et al (2012) diz que quando os recursos didáticos são trabalhados em sala de aula pelo professor, pode-se fazer possível a inclusão do aluno com cegueira ou baixa visão, isso é fundamental para que estes alunos aprendam e se 
aproximem de conceitos que antes, eram apenas ideias inteiramente abstratas em suas imaginações. $\mathrm{O}$ bom uso desses materiais pode favorecer também alunos que são videntes e fazer com que a aula para estes, se torne mais dinâmica, atraente e contextualizada.

Mansini e Bazon (2005) comentam que efetivar a inclusão requer clareza em certas situações, como: convívio com o aluno, clareza na própria ação do educador, observação sobre o aluno para formar uma concepção a respeito dele e expectativas sobre o que o aluno cego ou com baixa visão pode realizar.

Um fator importante para o sucesso dessa inclusão é a instituição ouvir e atender a necessidade de professor e aluno, para ambos trabalharem com os materiais necessários para facilitar o processo de ensino-aprendizagem, ajudando no rendimento do aluno. Essa ação colabora com o professor que terá material para auxilia-lo com os alunos que demandam um ensino especializado. (VARGAS, 2006)

O fato de que o Ensino Superior é cada vez mais acessível e a formação universitária, cada vez mais essencial para o desenvolvimento profissional e a obtenção de um emprego melhor leva ao questionamento sobre o caráter inclusivo das universidades (VARGAS, 2006).

Pensando em contribuir com as demandas do processo de inclusão no Ensino Superior, especialmente no contexto do curso de Ciências Biológicas, é que se buscou identificar as demandas de aprendizagem de sujeitos com deficiência visual e, visando atender a essas demandas, criou-se materiais que pudessem contribuir com a dimensão instrumental de acessibilidade.

\section{METODOLOGIA}

Durante a proposição do projeto desta pesquisa, o objetivo era realizar uma pesquisa dentro de uma IES do Distrito Federal, direcionada a algum aluno deficiente visual que estivesse cursando Ciências Biológicas, porém devido a algumas intercorrências durante o processo de aprovação do projeto pelo Comitê de Ética e Pesquisa (CEP), a pesquisa teve de ser redirecionada.

Para essa pesquisa,então, foi realizada uma busca bibliográfica, de forma aplicada, buscando resultados qualitativos que pudessem embasar e levar à criação de materiais didáticos adaptados a alunos cegos para o ensino das matérias de Ciências Biológicas. 
O foco da pesquisa foi a identificação de dificuldades enfrentadas por alunos cegos e com baixa visão dentro do ensino superior para o curso específico das Ciências Biológicas.

O objetivo da pesquisa bibliográfica era encontrar artigos que descrevessem essas dificuldades para alunos deficientes visuais no acesso ao ensino superior, independente do curso ou da universidade.

As bases de busca utilizadas nessa pesquisa foram a EBSCO e o Google Scholar. Foram buscados materiais de cunho científico aplicado ao campo da educação utilizando as seguintes palavras-chave: cegueira, baixa visão, educação superior, educação inclusiva, materiais didáticos adaptados, Ciências Biológicas, Biologia.

O tempo determinado para que inclusão dos artigos fosse aceita dentro desta pesquisa era o intervalo de dezesseis anos (2000-2016), para a busca de dados mais atualizados dentro do campo da educação inclusiva. Dentro dos artigos encontrados, foram buscadas informações principalmente, sobre a vivência acadêmica diária desses alunos, quais eram seus maiores desafios, a estrutura das universidades para recebê-los e o preparo dos professores universitários para a recepção desses alunos em suas aulas.

Após a leitura dos artigos, todos os dados coletados foram analisados a fim de buscar três campos diferentes das Ciências Biológicas em que se identificasse uma maior necessidade de materiais adaptados de acordo com a demanda de atividade visual necessária para o ensino dessas matérias.

O último passo da pesquisa foi a idealização e a criação desses materiais. Foram escolhidas três grandes áreas das Ciências Biológicas a partir de uma pesquisa em livros didáticos de Biologia e o conhecimento das pesquisadoras sobre as matérias que são desenvolvidas ao longo do curso, pois ambas são graduandas da área. Os materiais foram criados a partir do uso de matéria prima comum e barata, encontrada principalmente em papelarias e em nossas próprias casas (como papel cartão, isopor, cartolina, barbante, EVA, etc), com a finalidade de facilitar a reprodução desses materiais dentro de universidades ou escolas que necessitarem do mesmo.

Os modelos foram pensados de forma a atenderem os dois tipos de deficientes visuais. Também foi utilizada a escrita em braile, feita com cola colorida para a textura em alto relevo. Para o uso da escrita braile foi realizado uma pesquisa 
na internet, para sabermos como era o alfabeto e as letras foram reproduzidas cautelosamente.

\section{RESULTADOS}

Do total de artigos científicos pesquisados, delimitou-se ao número de sete artigos que atendiam melhor aos objetivos a serem trabalhados no desenvolvimento da pesquisa.

Desses, quatro tratavam sobre o espaço do aluno com deficiência visual dentro do ensino superior, dois tratavam sobre a inclusão de pessoas com necessidades especiais em um geral no ambiente universitário e um tratava sobre materiais didáticos para o ensino de Ciências Biológicas.

Os artigos utilizados foram: Masini; Bazon (2005), Vargas (2006), Orlando et al (2009), Holanda; Cunha (2011), Faria (2013), Santos; Mendonça (2015), Schuetzer (2015). Todos listados nas referências bibliográficas deste trabalho.

Em todos os artigos lidos, o principal ponto de reclamação era o mesmo: a falta de preparo dos docentes para receber um aluno com deficiência visual em sala de aula. A maioria dos professores estão acostumados com a integração de alunos deficientes, ou seja, sua inclusão no espaço escolar sem aprendizagem efetiva ou adaptação da IE para as necessidades daquele aluno, como materiais didáticos, espaços físicos e treinamento efetivo para a dinâmica da sala de aula.

O principal ponto em comum apresentado eram as aulas laboratoriais, onde os alunos não poderiam ter autonomia na realização dos estudos. Mas também, a falta de conhecimento com metodologias e materiais diferenciados que poderiam ser usados para a aprendizagem efetiva desses alunos.

O segundo ponto de reclamação era a falta de estrutura física acessível a esses alunos. A maior parte das pesquisas também apresentava a falta de materiais para esses alunos, como livros em braile, ledores, material ampliado, entre outros que facilitariam o processo acadêmico dos mesmos.

Diante da demanda apresentada pelos artigos após análise dos dados coletados, e conhecendo o campo das Ciências Biológicas, pois somos alunas do curso, foram escolhidas três grandes áreas para a criação dos materiais didáticos táteis e adaptados a alunos deficientes visuais. As áreas escolhidas foram: a biologia celular, a botânica e a microbiologia. 
Dentro dessas grandes áreas, nosso desafio era encontrar um conteúdo específico para a proposição dos materiais. Para a biologia celular foi escolhido um modelo tátil aliado ao braile do processo de formação do cromossomo, que nesta seção iremos chamar de modelo $n^{\circ}$ 1. No campo da botânica, foi realizado um painel tátil também com o uso do braile para mostrar as partes que compõem uma flor, interna e externamente, nesta seção iremos chamar de modelo nำ. Já na área da microbiologia, foi escolhido desenvolver um material didático tridimensional com áreas táteis do vírus bacteriófago, nesta seção iremos chamar de modelo no3.

$O$ entendimento do processo de formação de um cromossomo pode ser quase impossível para alunos com cegueira e de difícil compreensão para alunos com baixa visão, uma vez que o processo não é visível nem mesmo em microscópio. O modelo tátil criado engloba texturas e cores, a fim de atender tanto os alunos com deficiência visual quanto alunos videntes.

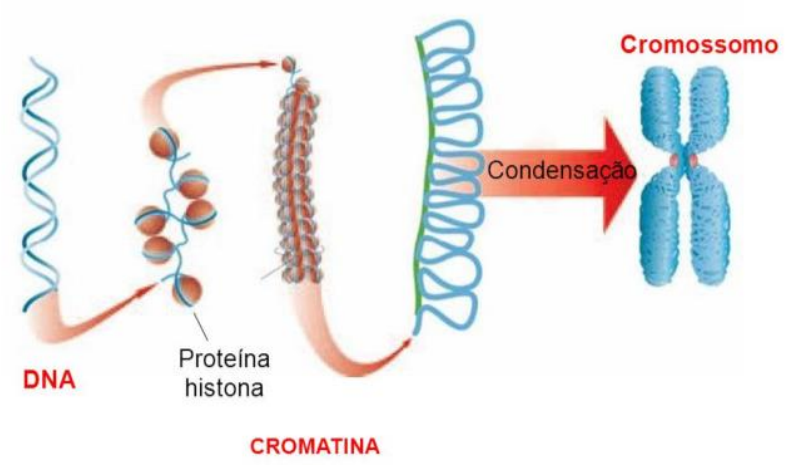

Figura 1: Imagem explicativa sobre o processo de formação do cromossomo utilizada como base para o desenvolvimento do modelo didático 꿀. Fonte: Google Imagens
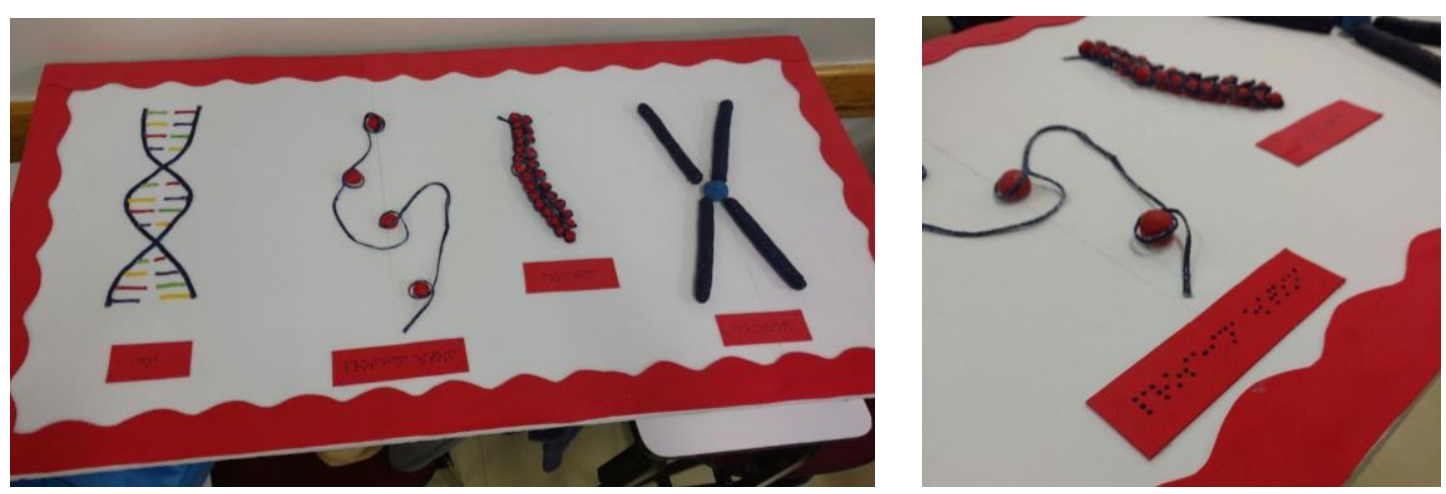

Figuras 2 e 3: Modelo didático criado. Painel tátil sobre a formação do cromossomo. Detalhes ampliados do braile.

O objetivo deste painel tátil é fazer com que os alunos com deficiência visual pudessem usar as mãos para tocar e sentir as texturas diferentes entre os materiais 
para entender o processo exemplificado. As quatro placas em braile embaixo de cada figura representam respectivamente: DNA, proteínas histonas, cromatina e cromossomo.

Para esse material didático foram utilizados os seguintes materiais: placa de isopor e EVA para compor a base do painel. Barbante com cola branca, pintado com tinta de tecido para compor o DNA e a cromatina. Massinha de modelar para representar as proteínas histonas. Todas as partes do cromossomo foram coladas na base com cola quente e cola de isopor. As placas táteis em braile foram feitas com EVA e cola colorida.

O modelo no2 foi criado com o intuito de auxiliar o entendimento dos alunos em sala de aula sobre a estrutura de uma flor. Muitas vezes os professores levam as flores da natureza para os laboratórios para que os alunos possam observar as estruturas externas e fazer cortes para observar as estruturas internas, o que pode dificultar o aprendizado dos alunos deficientes visuais.

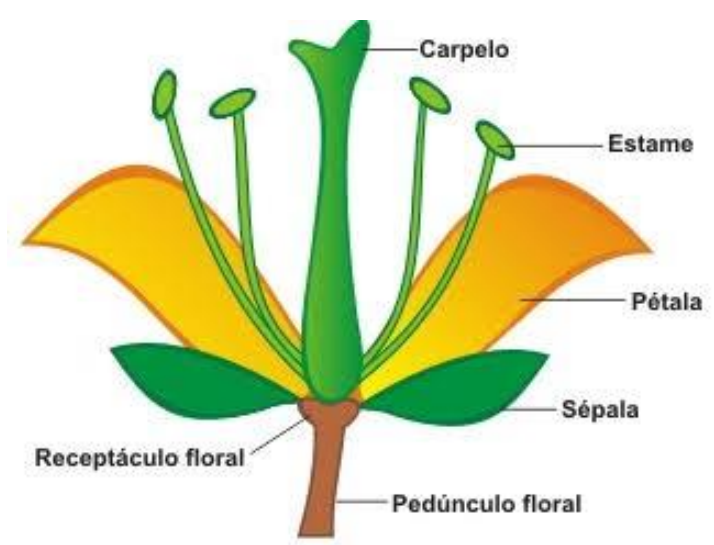

Figura 4: Imagem explicativa sobre a morfologia vegetal de uma flor, utilizada como base para o modelo didático ㄲo2. Fonte: Blog Diário Florestal
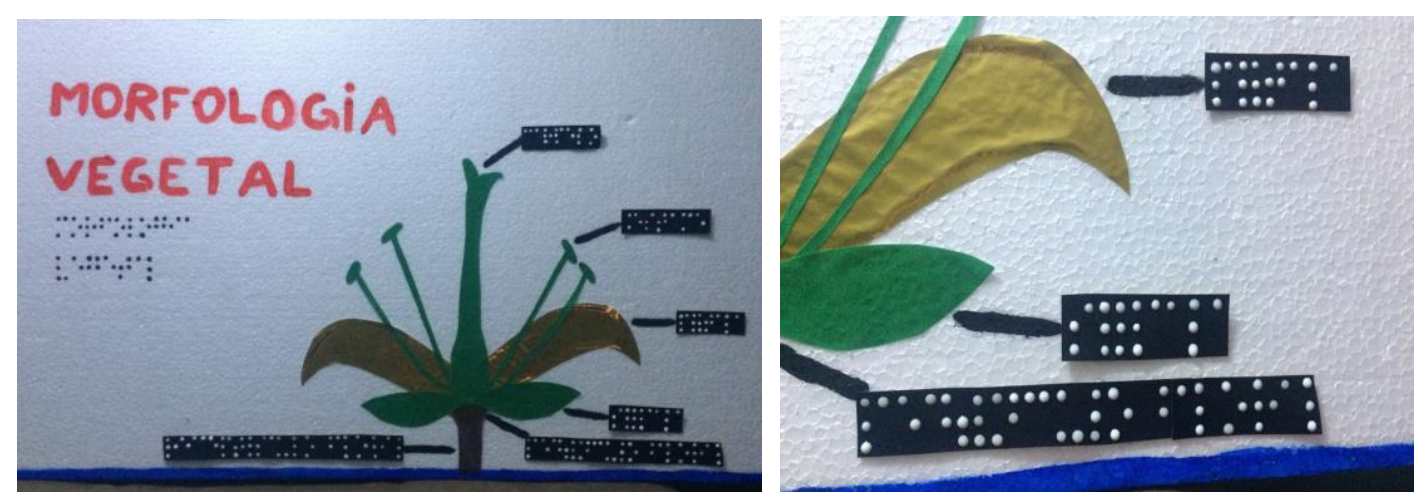

Figuras 5 e 6: Modelo tátil texturizado sobre a morfologia vegetal da flor. Detalhes da escrita em braile. 
O modelo n2 também buscava atender ambos os públicos com deficiência visual, com o maior foco sendo nos alunos cegos. A estrutura da flor é bem simples e foram utilizados materiais para representar suas partes mais marcantes.

Esse modelo foi feito com os seguintes materiais: placa de isopor para a base. Para a flor foram utilizados papel laminado na parte amarela e papel camurça para a parte verde. Para as placas em braile foram usados tiras de EVA e cola colorida para a parte em alto relevo.

O terceiro modelo foi pensando como um modelo tridimensional do vírus bacteriófago, o mais marcante na microbiologia por conta de sua estrutura única. Por se tratar de um vírus, não é visível a olho nu e para ser exemplificado, é necessário o uso de imagens para apresentar sua estrutura.

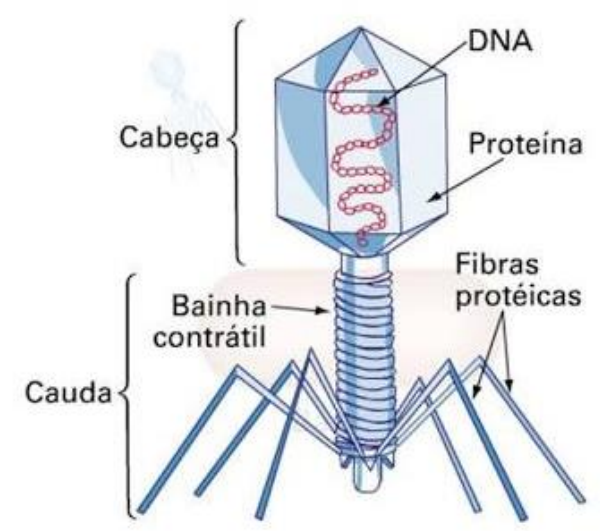

Figura 7: Imagem mostrando a estrutura do vírus bacteriófago, utilizada como base para a criação do modelo didático ํㅡㄴ. Fonte: Google Imagens. 

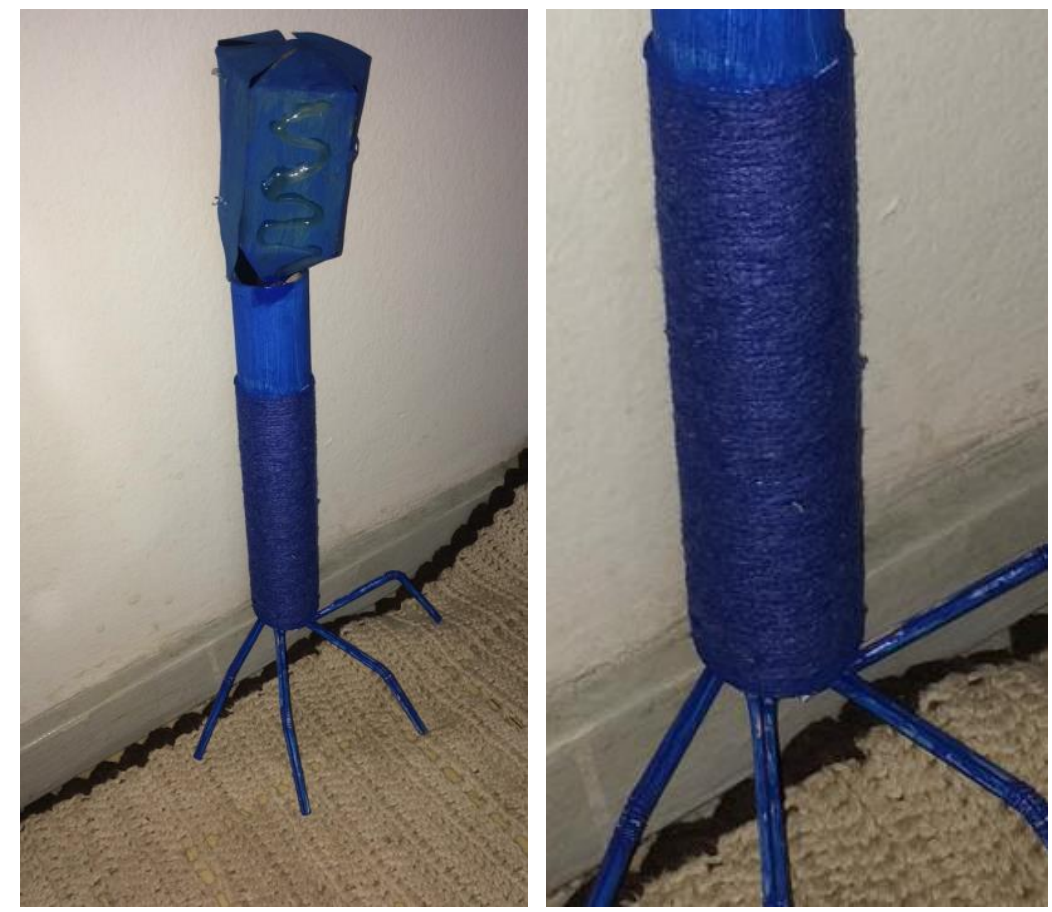

Figuras 8 e 9: Modelo didático sobre a estrutura do vírus bacteriófago, montado pelas pesquisadoras. Zoom na parte tátil texturizada indicando a bainha contrátil.

O modelo $n^{0} 3$ foi pensando principalmente para os alunos com baixa visão, por apresentar as partes ampliadas de cada estrutura. O modelo também poderia ser utilizado no ensino de alunos cegos com o auxílio de professores explicando cada parte enquanto o aluno utiliza o tato, e também com alunos videntes.

Para o último modelo foram utilizados os materiais: rolo de papel toalha para o corpo do vírus. Papel cartão dobrado para a cabeça. A bainha contrátil foi feita com barbante e tinta guache. As fibras proteicas foram feitas com canudos.

Todos os materiais didáticos apresentados neste trabalho não foram testados com alunos deficientes visuais e por isso, os dados apresentados quanto aos mesmos são proposições.

\section{CONSIDERAÇÕES FINAIS}

A partir deste estudo foi possível reunir dados de pesquisas já realizadas e identificar os maiores desafios enfrentados por alunos deficientes visuais em um curso superior de Ciências Biológicas e apresentar alguns novos recursos e alternativas que podem ser utilizados por professores em suas aulas, a fim de facilitar tanto o ensino quanto a aprendizagem no ambiente universitário. 
É importante salientar que a maioria das universidades adota o modelo de integração de alunos com NEE, e não inclusão. E essa é a realidade que se deve buscar mudar durante os próximos anos, para que estes alunos possam ter as mesmas oportunidades e experiências de aprendizagem que alunos com condições normais. Fazendo isso, transformamos a realidade social desses alunos, mostrando a eles que qualquer que seja a área onde os mesmos queiram atuar, é possível sim, realizando práticas e metodologias diferentes, adaptadas para o público a ser trabalhado.

Os resultados desta pesquisa abrem um leque de oportunidades para pesquisas futuras no campo da inclusão de alunos deficientes visuais. Os modelos didáticos aqui apresentados podem ser utilizados para uma futura pesquisa de validação em salas de aulas do ensino básico ou do ensino superior, para observar se os mesmos possuem potencial de uso real em sala de aula.

A pesquisa aqui apresentada também pode ser utilizada como base para realização de uma pesquisa de campo ou estudo de caso, utilizando um aluno que se enquadra no perfil aqui descrito.

\section{REFERÊNCIAS BIBLIOGRÁFICAS}

ARAGÃO, Amanda Silva. Ensino de química para alunos cegos: desafios no ensino médio. 2012. Dissertação (mestrado). Universidade Federal de São Carlos: UFSCar, $\quad$ SP. Disponível em < http://www.infoteca.inf.br/endipe/smarty/templates/arquivos_template/upload_arquivo a/acervo/docs/3432p.pdf> Acesso em novembro de 2015.

CARROLL, Thomas J. Cegueira: 0 que é, o que faz e como viver com ela. Campanha Nacional de Educação dos Cegos do Ministério da Educação e Cultura, 1968 - São Paulo, Brasil.

CASTRO, Helena C., et al. Ensino Inclusivo: um breve olhar sobre a educação inclusiva, a cegueira, os recursos didáticos e a área de biologia. REVISTA PRÁXIS, Ano VII, n. 13, janeiro de 2015. 
COSTA, Elaine Cristina Pereira; DE BARROS, Marcelo Diniz Monteiro. Luz, câmera, ação: o uso de filmes como estratégia para o ensino de Ciências e Biologia. Revista Práxis, v. 6, n. 11, 2014.

FARIA, Catarina Pereira. Inclusão de alunos com necessidades educativas especiais no ensino superior: Estudo exploratório sobre as perceções dos docentes. Universidade da Madeira, UMA. Tese de Doutorado. Funchal, Portugal. 2013.

Disponível em:

http://repositorio.uma.pt/bitstream/10400.13/509/1/MestradoCatarinaFaria.pdf> Acesso em janeiro de 2016.

HOLANDA, Maria Lucia de Souza; CUNHA, Renata Cristina Oliveira Barrichelo. Inclusão da pessoa cega no Ensino Superior: perspectivas de acesso, permanência e aproveitamento acadêmico. $9^{\circ}$ Amostra Acadêmica da UNIMEP. Piracicaba, São Paulo. 2011. Disponível em: < http://www.unimep.br/phpg/mostraacademica/anais/9mostra/5/332.pdf> Acesso em 26 de dezembro de 2015.

MASINI, Elcie; BAZON, FVM. A inclusão de estudantes com deficiência no ensino superior. Revista Psicologia da Educação, 2005. São Paulo. Disponível em: < http://flacso.redelivre.org.br/files/2012/07/424.pdf> Acesso em janeiro de 2016.

MINISTÉRIO DA EDUCAÇÃO. Orientações para implementação da política de educação especial na perspectiva da educação inclusiva. Brasil, 2015. Disponível em:

http://portal.mec.gov.br/index.php?option=com_docman\&view=download\&alias=1723 7-secadi-documento-subsidiario-2015\&category_slug=marco-2015pdf\&ltemid=30192> Acesso em 20 de outubro de 2015.

NEPOMUCENO, Gabriella $M$. et al. The value of safety and practicality: Recommendations for training disabled students in the sciences with a focus on blind and visually impaired students in chemistry laboratories. Journal of Chemical Health and Safety, v. 23, n. 1, p. 5-11, 2016. 
ORLANDO, Tereza Cristina et al. Planejamento, montagem e aplicação de modelos didáticos para abordagem de Biologia Celular e Molecular no Ensino Médio por graduandos de Ciências Biológicas. Revista de Ensino de Bioquímica, v. 7 , n. 1, p. 1-17, 2009.

SANTOS, Roseli Albino dos; MENDONÇA, Suelene Regina Donola. Universitários cegos: A visão dos alunos e a (falta de visão) dos professores. Revista Científica e-Curriculum, v. 13, n. 4, p. 888-907, 2015.

SASSAKI, Romeu Kazumi. Inclusão: o paradigma do século 21. Revista Inclusão, v. 1 , n. 1 , p. 19-23, 2005. Disponível em: < http://www.apabb.org.br/visualizar/Incluso-o-paradigma-do-seculo-21/1182> Acesso em março de 2016.

SCHÜETZER, Darlene Barbosa. Uma face da confessionalidade: a inclusão de pessoas com necessidades educacionais especiais no ensino superior. Revista de EDUCAÇÃO do Cogeime, v. 24, n. 46, p. 45-58, 2015.

VARGAS, Gardia Maria Santos de. A inclusão no ensino superior: a experiência da disciplina Prática Pedagógica-prática de Ensino de uma turma de alunos cegos e com baixa visão. Ponto de Vista: revista de educação e processos inclusivos, n. 8, p. 131-138, 2006.

VAZ, José Murilo Calixto et al. Material didático para ensino de biologia: possibilidades de inclusão. Revista Brasileira de Pesquisa em Educação em Ciências, v. 12, n. 3, 2012. Disponível em < 1https://www.researchgate.net/profile/Tereza_Orlando2/publication/273359243_Dida ctDi_Material_for_Biology_Education_Inclusion_Possibilities/links/54ff19c60cf2741b6 9f2e287.pdf> Acesso em novembro de 2015. 